\title{
A relação entre o Sistema Nacional de Inovação (SNI) e valoração de tecnologias
}

A inovação aumenta a competitividade, gera riqueza e desenvolvimento não só às empresas, mas em países também. Na relação da inovação com geração de valor e políticas públicas de incentivo à inovação, se encontra o SNI - Sistema Nacional de Inovação, ou seja, uma gama de instituições interligadas para criar, armazenar e transferir o conhecimento. Neste contexto, destaca-se a transferência de tecnologia e a valoração de tecnologias, agentes responsáveis para que uma tecnologia se transforme em inovação. Assim o presente artigo, faz a seguinte problematização: quais os métodos de valoração de inovação mais usados nos ditos sistemas de inovações maduros? Trata-se de uma pesquisa descritiva, com apuração de informações por meio do levantamento bibliográfico. Portanto, foi observado que um SNI estruturado contribui para a difusão da inovação, produção de novos produtos e por consequência para a existência de ferramentas de valoração que contribuíam de fato para o fortalecimento da ideia de desenvolvimento a partir do fomento da inovação.

Palavras-chave: Sistema Nacional de Inovação; Valoração; Inovação.

\section{The relationship between the National Innovation System (SNI) and technology valuation}

\begin{abstract}
Innovation increases competitiveness, generates wealth and development not only for companies, but in countries as well. In the relationship between innovation and value generation and public policies to encourage innovation, there is the SNI - National Innovation System, that is, a range of interconnected institutions to create, store and transfer knowledge. In this context, the transfer of technology and the valuation of technologies stand out, responsible agents for a technology to be transformed into innovation. Thus, the present article makes the following problematization: what are the innovation valuation methods most used in the said mature innovation systems? It is a descriptive research, with information obtained through bibliographic survey. Therefore, it was observed that a structured SNI contributes to the diffusion of innovation, the production of new products and, consequently, to the existence of valuation tools that in fact contributed to the strengthening of the idea of development by fostering innovation.
\end{abstract}

Keywords: National Innovation System; Valuation; Innovation

Topic: Inovação Tecnológica

Reviewed anonymously in the process of blind peer.

João Leandro Cássio de Oliveira

Instituto Federal do Norte de Minas Gerais, Brasil http://lattes.cnpq.br/3671969664538027

http://orcid.org/0000-0002-8277-6851

joao.oliveira@ifnmg.edu.br

Francisco Horácio Pereira de Oliveira

Universidade Federal de Ouro Preto, Brasil

http://lattes.cnpq.br/2406391142535135

chico.horacio@gmail.com

João Francisco Sarno Carvalho (id)

Instituto Federal do Norte de Minas Gerais, Brasil

http://lattes.cnpq.br/5217806842201673

http://orcid.org/0000-0001-8815-4773

joao.carvalho@ifnmg.edu.br
Received: 10/04/2020

Approved: 29/07/2020
Sheldon William Silva (it)

Instituto Federal de Minas Gerais, Brasil

http://lattes.cnpq.br/5691436224279198

http://orcid.org/0000-0002-2473-5728

sheldonwilliamsilva@gmail.com
Referencing this:

OLIVEIRA, J. L. C.; OLIVEIRA, F. H. P.; CARVALHO, J. F. S.; SILVA, S. W. . A relação entre o Sistema Nacional de Inovação (SNI) e valoração de tecnologias. Engineering Sciences, v.8, n.2, p.91-103, 2020. DOI: http://doi.org/10.6008/CBPC2318-3055.2020.002.0010 


\section{INTRODUÇÃO}

Inovação é um termo constante no meio empresarial, principalmente em um cenário de competitividade excessivamente alta, assim inovar se torna quase uma obrigação para as organizações se tornarem mais competitivas. Shumpeter (1934) apontou para a inovação como um meio diferencial em relação a concorrência. Para ele existe uma forte correlação entre o desenvolvimento, o empreendedor, a inovação e a concorrência, em sua visão a inovação é força de desenvolvimento, e o empreendedor é quem impulsiona essa inovação, e por fim, quem motiva todo esse processo é a concorrência.

Entre os diversos fatores que impulsionam a inovação, o investimento se mostra como um dos mais importantes já que não se inova sem dedicação de tempo e financeira. Na análise clássica das finanças, só vale investir quando se tem um retorno, assim de forma básica para avaliar um preço de um produto ou serviço é necessário verificar o benefício desse produto ou serviço. Dessa forma, para que a inovação seja efetiva, aos olhos do investidor, ela precisa trazer retorno.

O investimento é um sacrifício de um recurso atual para obtenção de retorno/ganho futuro. Para se investir em inovação é fundamental que se tenha um ganho no futuro para que essa inovação seja sustentável. Em contabilidade para que tenhamos condições de investir é essencial que existam meios de financiamento para subsidiar esse investimento. Investimentos são feitos com objetivo de aumento ou ganho patrimonial.

De acordo com Faria et al. (2010) o patrimônio de uma entidade é composto por Ativo, Passivo e Patrimônio Líquido. Os Ativos são representados por bem e direitos, ou seja, onde estão sendo aplicados os recursos da entidade, o Passivo e o Patrimônio Líquido são representados pelas obrigações ou as fontes de onde são retirados os recursos para financiar as aplicações. Os recursos do Patrimônio líquido derivam dos capitais dos sócios, enquanto os recursos do Passivo dos capitais de terceiros.

Assim, de acordo com as informações dos autores acima, podemos entender que para se ter um bem, é preciso ter uma fonte para financiar esse bem, ou seja, a inovação é um bem da entidade, sendo assim ela precisa de investimento, para ter investimento é necessário ter retorno, para ter retorno é preciso ter benefícios em relação ao custo, por fim para que seja contemplado esse ciclo (investimento, retorno e benefício) é vital a valoração do bem, no nosso caso a valoração da inovação.

Podemos estabelecer aqui uma divisão de dois grandes grupos de Bens de uma organização os Bens Tangíveis e os Bens Intangíveis. Para Marion (2007) o Ativo Tangível ou Corpóreo constitui de bens físicos, materiais, que se pode tocar, aquilo que os nossos olhos enxergam: estoques, veículos, terrenos, prédios, máquinas, móveis de escritórios, etc. Já o Ativo Intangível ou Incorpóreo ou Ativo Invisível são bens que não se pode tocar ou pegar, como marcas, patentes, processos, inovações.

Os Ativos Intangíveis são bens com características bem peculiares, pois para a sua existência são necessários investimentos significativos de recursos técnicos ou tecnológicos, financeiros e principalmente do fator tempo. Quando se trata de uma inovação esses recursos tendem a ser ainda mais dispendiosos, já que o tempo de geração da ideia, desenvolvimento e a sua disposição no mercado podem levar décadas ou 
até mesmo não se transformar em um ativo para a empresa.

Litan et al. (2003) ressaltam que ativos intangíveis são difíceis de avaliar, pois são bem heterogêneos e falta mercados organizados para negociá-los, em suma, não existe um padrão ou um modelo para uma objetiva valoração de um ativo intangível. Para inovar e a partir dessa inovação gerar riqueza, a empresa ou empreendedor necessita de apoio. Este apoio vem de um grupo articulado de instituições dos setores público e privado (agências de fomento e financiamento, instituições financeiras, empresas públicas e privadas, instituições de ensino e pesquisa, etc.) cujas atividades e interações geram, adotam, importam, modificam e difundem novas tecnologias, sendo a inovação e o aprendizado seus aspectos cruciais (OCDE, 2006).

Estas instituições criam assim um grande grupo de atores articulados e direcionados para a consolidação da inovação em um país ou região. Os países mais desenvolvidos são também os mais inovadores, investir em inovação é possuir um bem intangível para um país ou região, assim a partir do exposto podemos entender que este bem é chamado de Sistema Nacional de Inovação.

Portanto, a proposta deste trabalho justifica-se como fundamental ao compreender e relacionar as contribuições do sistema nacional de inovação para a estruturação de um mecanismo de valoração de inovação. Assim, o artigo problematiza-se essa perspectiva, a partir da seguinte questão: quais os métodos de valoração de inovação mais usados nos ditos sistemas de inovações maduros?.

Este trabalho tem por objetivo geral levantar bibliograficamente as ferramentas de valoração de inovação mais usadas em sistemas de inovações consolidados. Pretende-se de modo específico: (i) verificar quais são os métodos de valorar tecnologias inovadoras mais usados; e (ii) relacionar sistemas de inovação com métodos de valoração.

\section{REVISÃO TEÓRICA}

\section{Inovação}

É notória a ideia de que vivemos em um ambiente de grande competitividade de mercado e de altas transformações, o que afeta diretamente as opções de compra por parte do consumidor, estimulando novos mercados e criando novas percepções em mercados já consolidados. Alguns autores, como Rados et al. (2015) defendem que sem inovar a empresa reduz significativamente sua capacidade competitiva.

A competitividade incentiva o investimento em inovações e por meio disso as empresas se veem obrigadas a criar processos, ideias, tecnologias. Mas, há de se chamar atenção para a diferença em entre a inovação e a invenção. Para Schumpeter (1997) a criação de um novo produto ou artefato que poderá ter ou não uma relevância econômica é chamada de invenção, de forma que essa invenção somente será uma inovação quando a mesma for tratada ou transformada em mercadoria de maneira que possa ser economicamente explorada.

Freeman et al. (2008) entendem a invenção como um ato de criar um novo conhecimento, mesmo tendo uma patente de uma invenção, não se pode dizer que com isso configura uma inovação. Não se pode também descolar uma ideia da outra, ou seja, separar a inovação da invenção, conforme ressalta Santos 
(2005), inovação não existe sem a invenção, da mesma maneira que não existe técnicas sem tecnologia.

Para Schumpeter (1997) inovação é uma combinação de elementos ou recursos que já existem para produção de novos produtos, ou produtos que já existem, mas produzidos com mais eficiência. Segundo o Manual de Oslo (2006) inovação é:

É a implementação de um produto (bem ou serviço) novo ou significativamente melhorado, ou um processo, ou um novo método de marketing, ou um novo método organizacional nas práticas de negócios, na organização do local de trabalho ou nas relações externas. (OCDE, 2006)

Ainda de acordo com o Manual de Oslo as inovações são diferenciadas por quatro tipos: de produto, de processo, de marketing e organizacional. O Quadro 1 apresenta cada um desses tipos de inovação:

Quadro 1: Definição dos tipos de inovação.

\begin{tabular}{|l|l|}
\hline $\begin{array}{c}\text { Tipo de } \\
\text { inovação }\end{array}$ & \multicolumn{1}{c|}{ Definição } \\
\hline De produto & $\begin{array}{l}\text { É a introdução de um bem ou serviço novo ou significativamente melhorado no que concerne a suas } \\
\text { características ou usos previstos. Incluem-se melhoramentos significativos em especificações técnicas, } \\
\text { componentes e materiais, softwares incorporados, facilidade de uso ou outras características funcionais }\end{array}$ \\
\hline De Processo & $\begin{array}{l}\text { É a implementação de um método de produção ou distribuição novo ou significativamente melhorado. } \\
\text { Incluem-se mudanças significativas em técnicas, equipamentos e/ou softwares. }\end{array}$ \\
\hline De Marketing & $\begin{array}{l}\text { É a implementação de um novo método de marketing com mudanças significativas na concepção do produto } \\
\text { ou em sua embalagem, no posicionamento do produto, em sua promoção ou na fixação de preços. }\end{array}$ \\
\hline Organizacional & $\begin{array}{l}\text { É a implementação de um novo método organizacional nas práticas de negócios da empresa, na organização } \\
\text { do seu local de trabalho ou em suas relações externas. }\end{array}$ \\
\hline
\end{tabular}

Fonte: OCDE - Manual de Oslo (2006).

Freeman (1968) classifica as inovações de acordo com seus impactos, assim elas podem ser incrementais e radicais. As inovações Incrementais são consideradas as mais elementares nas mudanças tecnológicas, abrangendo melhorias de qualidade e design de produtos, melhoria de layouts em processos, novas arrumações logísticas e práticas de venda. As inovações radicais são representadas por uma inovação geralmente fruto de atividades de P\&D e tem um caráter descontínuo no tempo e nos setores, é chamada por radical, pois rompe as trajetórias existentes, inaugurando uma nova rota tecnológica.

Na década de 1990 foi inserida outra classificação de inovação, a partir dos estudos de Clayton Christensen, a chamada inovação disruptiva. De acordo com Christensen (1997) as inovações disruptivas são aquelas que provocam uma ruptura no antigo modelo de negócios. Elas normalmente favorecem o aparecimento de novos entrantes. Podemos entender, grosso modo, que a inovação disruptiva é aquela geradora de novos mercados, como novos conceitos de qualidade para novos consumidores.

Compreender conceitos e tipos de inovação nos permite conhecer a importância das inovações na sociedade. Uma empresa com cultura inovadora, é uma empresa disposta a mudança, a quebrar paradigmas e alinhada com os diferenciais competitivos que o mundo atual exige.

\section{Sistema Nacional de Inovação e Valoração}

A inovação, de acordo com Cassiolato et al. (2005), é o produto da incorporação de conhecimento e das atividades produtivas, e assim pode ser entendida como variável estratégica para a competividade de países e organizações. Alguns países se destacam no cenário mundial por saberem explorar a inovação em suas estratégias de desenvolvimento. Neste cenário de desenvolvimento estratégico a partir da inovação é 
que pretendemos estudar o papel do SNI - Sistema Nacional de Inovação na valoração de uma inovação. Um SNI é conceituado como:

Conjunto de instituições que (conjunta e individualmente) contribuem para o desenvolvimento e difusão de novas tecnologias. Essas instituições fornecem o quadro dentro do qual os governos formam e implementam políticas para influenciar o processo de inovação. Como tal, é um sistema de instituições interligadas para criar, armazenar e transferir o conhecimento, as habilidades e os artefatos que definem as novas tecnologias. (METCALFE, 1995; OCDE, 2006)

Para Sharif (2006) os atores dentro de um sistema de inovação, bem como fatores contextuais, são elementos importantes de qualquer sistema dado para a criação e uso do conhecimento para fins econômicos. Tais atores de um sistema de inovação podem ser resumidos em três, o governo, as universidades e as empresas. Para que exista inovação, é necessário que a invenção esteja disponível no mercado, assim quem inova são as empresas, mas estas necessitam de um sistema articulado de pesquisa com políticas públicas voltadas para o incentivo à inovação.

Para Freemam et al. (2008) é o Estado quem faz o direcionamento do desenvolvimento tecnológico de um país, já que o mesmo tem a função de regulamentar os setores produtivos, objetivando assim o fortalecimento da inovação. Quanto as universidades e centros de pesquisas, são elas as responsáveis por fomentar o conhecimento tecnológico, base para alcance da inovação. Dessa maneira é fundamental que estes três agentes estejam relacionados para que um SNI tenha sucesso e efetividade.

Lundvall (2007) salienta que a estrutura da noção de um sistema é baseada na forma como as empresas aprendem, como esse ator se articula com os demais dentro de uma característica de qualidade das relações que ligam todas partes ao desempenho dos processos inovativos oriundos de um sistema estimulador do desenvolvimento a partir da inovação. Edquist (2005) ressalta quatro fatores que influenciam o desenvolvimento e difusão das inovações: (i) fornecimento de insumos de conhecimento para o processo de inovação: Fornecimento de P\&D e Construção de Competências; (ii) atividades do lado da demanda: Formação de mercado para novos produtos, Requisitos de qualidade de novos produtos; (iii) fornecimento de constituintes: Criação e remodelagem de organizações de novos campos de inovação, Redes por meio de mercados e outros mecanismo, Criação e Transformação de institucional; e (iv) serviços de suporte a empresas inovadoras: Atividades de incubação, Financiamentos de processos de inovação, Serviços de consultorias.

O objetivo do SNI neste trabalho foi apresentar, de forma resumida, como a articulação entre atores da inovação (universidades, governo e empresas) podem induzir o desenvolvimento através da disseminação da cultura da inovação. Um SNI bem fundamentado com as devidas distribuições de responsabilidades entre seus atores, facilita e estimula a ciclo da inovação e a transferência de tecnologia entre seus atores, que por sua vez fortalece a importância do estudo de valorar uma inovação, pois assim pode-se quantificar o retorno dos investimentos em inovação.

\section{Transferência de Tecnologia}

Historicamente o homem tem marcado a humanidade com o desenvolvimento de técnicas com o 
propósito de sobrevivência, adaptação de clima, alimentação, dentre outros. De acordo com Veraszto (2004) o desenvolvimento das técnicas possibilitou a evolução histórica do homem. Contextualizando as técnicas a cada época, nos permite compreender a ativa participação da tecnologia no progresso da sociedade, o que enriquece muito o conceito de tecnologia.

Para Almeida (1981, citado em CYSNE, 2005) a tecnologia, em linhas gerais é um processo que envolve os setores de ciência, de engenharia, de tecnologia, de produção e comercialização e de divulgação: nasce no setor que produz ciência (universidade), tem avanços nas aplicações científicas nos institutos de pesquisa, é projetada como produto, processo e serviço pelas empresas de engenharia. As matérias-primas e os equipamentos para o desenvolvimento do bem final são produzidas por empresas específicas; outras empresas utilizam os bens de produção e os projetos de seu processo para produzir a tecnologia que será comercializada e entregue ao consumidor final (ALMEIDA, 1981, citado em CYSNE, 2005). Alguns autores acreditam que a tecnologia tem uma definição mais ampla. De acordo com Gordillo (2001) a tecnologia é algo universal; um mesmo produto, serviço ou artefato poderia surgir em qualquer local e, consequentemente, ser útil em qualquer contexto.

É neste ambiente de utilidade da tecnologia que discutiremos a transferência de tecnologia. De acordo com Natal et al. (1998) o autodesenvolvimento ou aquisição são formas de obtenção de uma tecnologia. O autodesenvolvimento pode ser muito dispendioso, isso faz com que a aquisição de uma tecnologia já existente seja a maneira mais viável de uma organização possuir aquela tecnologia desejada. Segundo Rogers et al. (2001) a transferência de tecnologia é "a movimentação da inovação tecnológica de uma organização de Pesquisa e Desenvolvimento para uma organização receptora".

De acordo com o Manual de Oslo (OCDE, 2006) as tecnologias podem ser coletadas de acordo com três tipos de interações ou fontes: (i) fontes abertas de informação: informações disponíveis que não exigem a compra de tecnologia ou de direitos de propriedade intelectual, ou interação com a fonte; (ii) aquisição de conhecimentos e tecnologia: compras de conhecimento externo e/ou conhecimentos e tecnologias incorporados em bens de capital (máquinas, equipamentos, softwares) e serviços, que não envolvem interação com a fonte; e (iii) inovação cooperativa: cooperação ativa com outras empresas ou instituições públicas de pesquisa para atividades de inovação (que podem incluir compras de conhecimento e de tecnologia). A Tabela 1 apresenta as maneiras de obtenção de tecnologias:

Tabela 1: Fontes para transferências de conhecimento e tecnologia.

\begin{tabular}{l|l|l|l}
\hline \multicolumn{1}{c|}{ Tecnologias } & $\begin{array}{c}\text { Fontes abertas de } \\
\text { inovação }\end{array}$ & $\begin{array}{c}\text { Fontes para compra de } \\
\text { conhecimento e tecnologia }\end{array}$ & $\begin{array}{c}\text { Parceiros para } \\
\text { cooperação }\end{array}$ \\
\hline Fontes no Interior da empresa & $\mathrm{O}$ & & \\
\hline P\&D & $\mathrm{O}$ & & \\
\hline Produção & $\mathrm{O}$ & & \\
\hline Marketing & $\mathrm{O}$ & & \\
\hline Distribuição & $\mathrm{O}$ & $\mathrm{O}$ & 0 \\
\hline Outras empresas no grupo comercial & $\mathrm{O}$ & & \\
\hline Mercado externo e fontes comerciais & & $\mathrm{O}$ & \\
\hline Concorrentes & $\mathrm{O}$ & $\mathrm{O}$ & 0 \\
\hline Outras empresas na indústria & $\mathrm{O}$ & & 0 \\
\hline Clientes ou consumidores & $\mathrm{O}$ & $\mathrm{O}$ & 0 \\
\hline Consultores & & & 0
\end{tabular}




\begin{tabular}{|c|c|c|c|}
\hline & $\Omega$ & $\Omega$ & 0 \\
\hline & & & \\
\hline Laboratórios comerciais & $\mathrm{O}$ & $\mathrm{O}$ & $\mathrm{O}$ \\
\hline \multicolumn{4}{|l|}{ Fontes do setor público } \\
\hline Universidade e outras inst. De ensino & $\mathrm{O}$ & 0 & 0 \\
\hline Instituto de pesquisa governamentais & 0 & 0 & 0 \\
\hline Institutos de pesquisas privados & 0 & 0 & 0 \\
\hline $\begin{array}{l}\text { Serviços especializados públicos de } \\
\text { suporte à inovação }\end{array}$ & $\mathrm{O}$ & $\mathrm{O}$ & $\mathrm{O}$ \\
\hline \multicolumn{4}{|l|}{ Fontes de informações gerais } \\
\hline \multicolumn{4}{|l|}{ Divulgação de patentes } \\
\hline Conferências e encontros profissionais & 0 & & \\
\hline Feiras e exibições & $\mathrm{O}$ & & \\
\hline Assoc. e sindicatos trabalhistas & $\mathrm{O}$ & & \\
\hline Outras associações locais & $\mathrm{O}$ & & \\
\hline Contatos informais ou rede & 0 & & \\
\hline Padrões de agência de padronização & 0 & & \\
\hline $\begin{array}{l}\text { Regulações públicas (ambiente e } \\
\text { segurança) }\end{array}$ & $\mathrm{O}$ & & \\
\hline
\end{tabular}

Fonte: OCDE - Manual de Oslo (2006).

Partindo do pressuposto que na criação de uma tecnologia a entidade geradora da tecnologia precisou fazer investimentos para a viabilização da tecnologia, estudaremos a seguir a seguir o conceito de valoração de inovação e tecnologias.

\section{Valoração de inovação}

A inovação é um produto da associação de vários elementos, mas principalmente do capital intelectual e dos processos tecnológicos. O investimento seja ele financeiro ou de tempo é o que viabiliza uma inovação, assim nessa perspectiva, para Amaral et al. (2014) os investimentos em inovação dão origem a um ciclo que é forte determinante da riqueza das nações. Nesse processo, estão, de um lado, as universidades, institutos de educação, ciência e tecnologia, institutos de pesquisa e empresas que são responsáveis por gerar conhecimentos. De outro, estão os governos, que desenvolvem políticas industriais de apoio e estímulo às atividades de inovação e, também, o sistema financeiro, que compreende instituições públicas e privadas. Em conjunto, eles ofertam os recursos financeiros necessários ao financiamento da Pesquisa e Desenvolvimento (P\&D).

Estando o processo de inovação envolto de grandes investimentos é natural que se espere retorno dessas inovações e uma forma de conhecer o retorno é saber o valor da inovação. A inovação precisa constantemente de ser valorada e avaliada, seja para um processo de transferência de tecnologia, para aquisições ou fusões de empresas ou para participação de investidores (fundos, anjos, capital semente, dentre outros). É importante distinguirmos avaliação de valoração:

Avaliação é compreender o estágio de desenvolvimento da pesquisa, levando em consideração, se possível, benchmarks existentes para tecnologias de natureza similar (e.g., fármacos, softwares). Assim, é possível estimar de forma preliminar as atividades necessárias para levá-la ao mercado (i.e., comercializá-la) e o investimento necessário para a conclusão do desenvolvimento. (SANTOS et al., 2008)

A avaliação é um conceito complementar que a ajuda a estruturar um processo de valoração. Dessa maneira, valoração se define: 
Valoração não é prever o valor exato da tecnologia no momento de sua comercialização, mas fornecer, diante de todas as incertezas que caracterizam o processo de inovação tecnológica, um valor esperado que, de certa forma, capte os riscos e incertezas inerentes a este processo. (SANTOS et al., 2008)

A associação entre valoração e avaliação é fundamental para alcançar os objetivos deste trabalho, pois como já explicado, as inovações são bem subjetivos, do ponto de vista de maturação, estágio de desenvolvimento e uso. Portanto para estudar a valoração é salutar que os critérios de avaliação de uma inovação estejam bem robustos.

\section{METODOLOGIA}

A metodologia de pesquisa iniciou-se com o desbravamento do objeto de estudo para que possa ser compreendido. Para isso, seguiu-se as orientações metodológicas de Carvalho et al. (2018) que afirmam que ao se conduzir uma pesquisa científica, o pesquisador deve-se atentar às técnicas de pesquisa e criar ou escolher aquelas mais adequadas para o desbravamento do objeto. Após esse cuidado, a pesquisa deve ser caracterizada e o pesquisador deve evitar a utilização de receitas metodológicas (CARVALHO et al., 2018). Dito isso, essa pesquisa caracteriza-se como uma pesquisa descritiva com base no critério proposto por Cooper et al. (2003). Segundo esses autores, as pesquisas descritivas são aquelas que têm como objetivo primordial à descrição das características de determinada população ou fenômeno, ou então o estabelecimento de relações entre as variáveis.

Quanto aos meios de investigação, foi feito um levantamento bibliográfico por meio do Portal de Periódicos da Coordenação de Aperfeiçoamento de Pessoal de Nível Superior (CAPES) objetivando levantar os métodos de valoração de intangíveis ligados à inovação mais citados nesta fonte. O período pesquisado foi entre o ano de 2007 e 2017, através dos critérios de busca e pesquisa na literatura, foi utilizado o tema Valoração de Inovação e Valoração de Tecnologias, assim foram encontrados 9 textos, entre artigos e dissertações.

Para Vergara (2013) “A investigação exploratória é realizada em área que há pouco conhecimento acumulado e sistematizado". Tal levantamento teve como fontes principais: teses, dissertações, periódicos, dentre outras publicações científicas. Para Martins et al. (2009) a pesquisa bibliográfica procura discutir um determinado assunto, alicerçado em publicações científicas. Dessa forma, após feito o apanhado de metodologias de valoração, o critério de seleção das metodologias estudadas neste trabalho, foi feito a partir do maior número de repetição nos textos estudados. A partir deles, buscamos alcançar os objetivos deste trabalho.

\section{RESULTADOS E DISCUSSÃO}

Conforme a pesquisa bibliográfica, foram encontrados vários métodos de valoração de inovação e tecnologias, dentro deste universo destacamos os mais encontrados os seguintes métodos: Valoração por Custos, Método pela Renda, Opções Reais e Royalties $25 \%$. 


\section{Valoração por Custos}

A valoração baseada nos custos é um instrumento bastante comum e muito utilizado em Contabilidade e Auditoria. De acordo Aziz et al. (2012) este método se baseia na observância de todos os custos gerados no desenvolvimento da tecnologia, ou seja, para valorar uma tecnologia se faz necessário o levantamento ou registro de todo dispêndio de recursos (custo de pessoal, material, estrutura custos indiretos, dentre outros) para assim determinar o valor dessa tecnologia, assim de acordo com Flignor et al. (2006), a abordagem pelo custo valora a tecnologia pelo quanto se gastou para gerá-la.

A aplicação deste método pode ser entendida em duas aplicações, reprodução e substituição. De acordo com Wirtz (2012), a reprodução for feita a partir do levantamento dos custos considerados em uma idêntica réplica de um bem tecnológico, ao passo que, a substituição considera os custos de aquisição ou produção de um bem com benefícios equivalentes ao em desejado.

\section{Método pela Renda}

Método pela renda se baseia a partir da capacidade potencial de geração de renda da tecnologia, ou seja, a capacidade que uma tecnologia possui em gerar benefícios futuros. Dentro da perspectiva estuda-se o valor do dinheiro no tempo, fornecida pelo fluxo de caixa descontado - FDC.

O FDC pode ser entendido como uma técnica de avaliação que:

Captura todos os elementos que afetam o valor da empresa de maneira abrangente e, por constituir-se em uma técnica de natureza econômica, reflete de forma mais consistente o valor da empresa do que o valor obtido a partir de técnicas contábeis, as quais se baseiam no lucro contábil e não consideram o investimento exigido para gerar os lucros nem o momento em que eles ocorrem. (DAMODARAN, 1997)

Para Assaf Neto et al. (2002) um Fluxo de Caixa é uma ferramenta que confrontam as entradas com as saídas de valores monetários de um empreendimento em um futuro determinado (cinco, dez, vinte anos), esse confronto permite o diagnóstico de sobra ou falta de recursos. Para Copeland et al. (1995) um valor de um bem pode ser encontrado pelo Fluxo de Caixa Descontado, pois este é obtido pelo somatório de fluxos de caixas futuros, ao qual serão descontados a uma taxa apropriada ao seu nível de risco.

Esse valor do bem é obtido pelo cálculo do VPL - Valor Presente Líquido.

O valor presente líquido (VPL) considera explicitamente o valor do dinheiro no tempo. É considerada uma técnica sofisticada de orçamento de capital. Todas as técnicas desse tipo descontam de alguma maneira os fluxos de caixa da empresa a uma taxa especificada. Essa taxa comumente chamada de taxa de desconto, retorno requerido, custo de ou custo de oportunidade, consiste no retorno mínimo que um projeto precisa proporcionar para manter inalterado o valor de mercado da empresa. (GITMAN, 2010)

O VPL é calculado pela seguinte equação:

$$
V P L=\sum_{t=1}^{n} \frac{F C_{t}}{(1+k)^{t}}-F C_{0}
$$


$F C t$ é o fluxo de caixa no período t; e $\mathrm{k}$ é taxa mínima a que se espera que o investimento seja remunerado.

O VPL é valor da bem/tecnologia, segundo Aziz et al. (2012) este método é quem apresenta as vantagens econômicas estimadas no futuro.

\section{Teoria das Opções Reais - TOR}

Inovações e Tecnologias são elementos cercados por incertezas, nesse cenário apresenta-se a Teoria das Opções Reais - TOR. De acordo com Brandão et al. (2006) a TOR parte da ideia que um projeto é analisado não como uma obrigação, mas como uma opção, fazendo com que cada etapa do projeto passe por uma análise de decisão, a chamada árvore de decisão. Isso implica em tomar as decisões do projeto de acordo as análises de situações favoráveis deste projeto.

Podemos entender árvore de decisão como:

Árvores de decisão são ferramentas úteis para explorar flexibilidades e os possíveis desdobramentos dessas flexibilidades. Uma árvore de decisão é, basicamente, um diagrama que representa, de forma organizada, as decisões que podem ser tomadas, os eventos de incerteza associados ao projeto em questão e os resultados associados a cada combinação de eventos e decisões. Ela é formada por nós de decisão e por nós de incerteza, que representam eventos aleatórios. (TEBECHRANI, 2010)

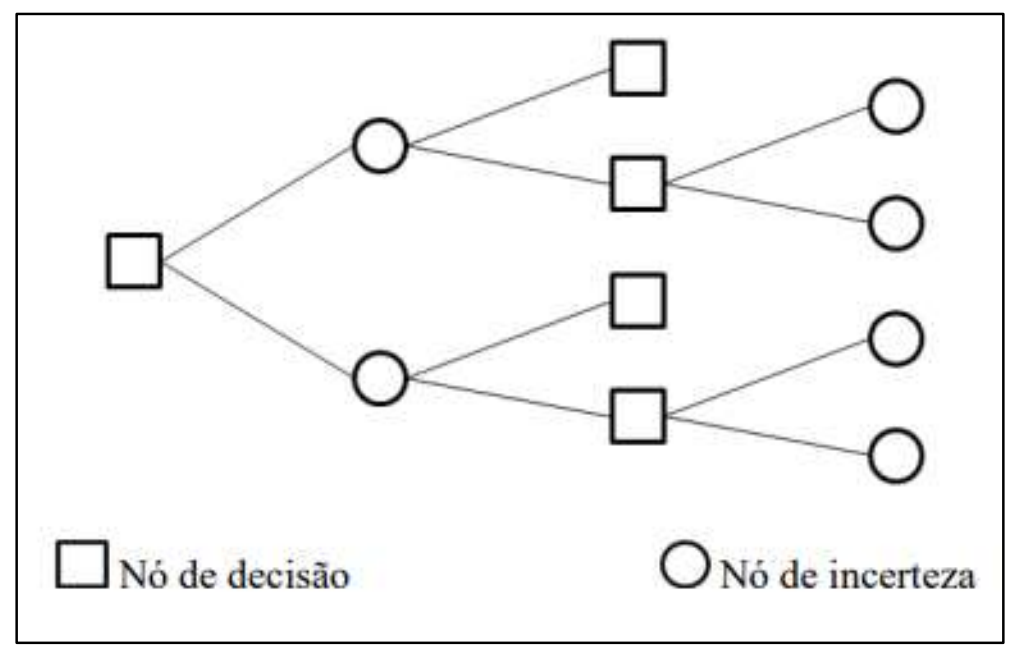

Figura 1: Modelo de árvore de decisão. Fonte: Tebechrani (2010).

De acordo com Souza (2006) a TOR pode ser assim calculada:

$$
\left.C=S N\left(\frac{\left(\ln (\mathrm{S} / \mathrm{E})+\left(\mathrm{r}+\frac{1}{2} \sigma^{2}\right) \mathrm{t}\right)}{\sigma \sqrt{\mathrm{t}}}\right)-E e^{-r t} N\left(\frac{\left(\ln (\mathrm{S} / \mathrm{E})+\left(\mathrm{r}+\frac{1}{2} \sigma^{2}\right) \mathrm{t}\right)}{\sigma \sqrt{\mathrm{t}}}\right)-\sigma \sqrt{\mathrm{t}}\right)
$$

Onde,

S é o valor presente dos fluxos de caixa;

E é custo do investimento do projeto; t é o tempo restante para investir;

6 é desvio padrão; $r$ é taxa de desconto livre de risco;

$\mathrm{N}$ é a função de distribuição para o custo do projeto.

A TOR apresenta ao analista as limitações de sucesso na busca de informações em projetos de inovações que não possuem dados históricos, dando a este analista a opção de continuar ou não com o 
projeto.

\section{Regra do 25\%}

A regra dos $25 \%$ é uma metodologia para cálculo de royalties. Para Barbosa (2014) royalties é uma forma de remuneração ligada ao direito de uso cedido pelo titular daquele patrimônio a um terceiro. Assim, entende-se que:

Royalty é uma palavra de origem inglesa que se refere a uma importância cobrada pelo proprietário de uma patente de produto, processo de produção, marca, entre outros, ou pelo autor de uma obra, para permitir seu uso ou comercialização. (BRASIL, 2014)

No contexto de royalties, de acordo com Goldscheider et al. (2007), a regra do $25 \%$ é um método de valoração baseado em uma cobrança de taxa de $25 \%$ a partir do lucro de tecnologia que incorporou o direito de propriedade intelectual em sua composição. Parr (2007) ressalta que este método pode ser aplicado na relação universidade empresa, onde as empresas remuneram as universidades com pagamentos de royalties pelo uso de tecnologias desenvolvidas.

\section{CONCLUSÕES}

Para iniciarmos nossas conclusões é vital voltarmos a premissa básica do conceito de valoração, Santos et al. (2008) ressaltam que valorar não obter o valor exato monetário de uma tecnologia ou inovação, mas sim um valor que seja capaz de captar os riscos e incertezas envolvidos neste processo. Através do levantamento bibliográfico referente ao tema, chegamos em quatro metodologias de valoração de inovação. O método baseado nos custos é o mais simples e por consequência o mais fácil de ser aplicado, por outro lado ele é bastante limitado, pois o quantitativo de recursos envolvidos não representará ganhos futuros aos riscos associados, assim como um mesmo montante de recursos não reproduzirá um bem tecnológico parecido.

Em relação ao método do Fluxo de Caixa Descontando trata-se de uma metodologia bastante difundida e muito usado em empresas de bases tradicionais. Sua aplicação em valoração de bens tecnológicos, como inovação também é bastante aceita, desde que se tratar de uma inovação incremental, pois a mesma pode estimar cenários de acordo com os produtos que se pretende substituir. Para aplicação em inovação radical, trata-se de uma ferramenta com pouca ou nenhuma aplicação, pois neste caso não é possível estimar cenários de fluxos de caixas para uma tecnologia que ainda não existe mercado.

Sobre a Teoria das Opções Reais, para vários autores, trata-se de uma evolução do método do FDC, mas diferentemente do FDC leva em conta as incertezas e as decisões gerenciais. Por outro lado, a TOR é bastante complexa, já que exige uma capilaridade muito grande de informações, em empreendimento muito embrionário, onde as informações são escassas e as incertezas são muitas, a TOR tem pouca utilidade. A regra dos $25 \%$ é muito útil, pois além de muito simples no cálculo vem sendo utilizada, sendo uma boa ferramenta para ponto de partida em licenciamentos. Mas com a limitação de ser usadas em tecnologias com boa maturidade, ou com capacidade de gerar caixa.

Dessa forma, acreditamos que para se ter bons métodos de valoração é necessário ter organização 
e ecossistemas fortes de inovação, como o caso de SNI. Há de notar que quanto mais maduro for um Sistema Nacional de Inovação, maiores serão as possibilidades de haver negócios neste meio, pois sem efetivas políticas públicas de incentivo à inovação e fortalecimento das parcerias entre os atores (universidades, empresas e governo), a produção de tecnologias e a transformações das mesmas em inovações, diminui muito a efetividade de um método de valoração. Portanto, é fundamental a existência de um SNI estruturado, para assim haver a difusão da inovação, produção de novos produtos e por consequência existirem ferramentas de valoração que contribuíam de fato para o fortalecimento da ideia de desenvolvimento a partir do fomento da inovação.

\section{REFERÊNCIAS}

AZIZ, K.; HARRIS, H.; AZIZ, N. A. A.. Intellectual Property Valuation Decision Support System for University Research Output: A Conceptual Model. Communications, 2012.

AMARAL, H. F.; IQUIAPAZA, R. A; CORREIA, L. F.; AMARAL, G. H. O.; VIEIRA, M. V.. Avaliação de Ativos Intangíveis: Modelos alternativos para determinação do Valor de Patentes. Revista de Gestão, Finanças e Contabilidade, v.4, p.123-143, 2014.

ASSAF NETO, A.; SILVA, C. A. T.. Administração do Capital de Giro. 3. ed. São Paulo: Atlas, 2002.

BARBOSA, D. B.. Da inoponibilidade da patente prorrogada em face dos concorrentes anteriores. 2014.

BRANDÃO, L.; CURY, M. Q.. Modelagem híbrida para concessões rodoviárias pioneiras com o uso da teoria das opções reais. Gestão e Org. Revista Eletrônica de Gestão Organizacional, Recife, v.10, n.4, p.121-140, 2006.

CARVALHO, J. F. S.; PIMENTA, C. A. M.; OLIVEIRA, S. D.. Entre a ciência e a complexidade dos novos objetos de pesquisa: a construção interdisciplinar de uma metodologia de pesquisa científica. Eccom: Educação, Cultura E Comunicação, v.9, p.105-116, 2018.

CASSIOLATO, J. E.; LASTRES, H. M. M.. Sistemas de inovação e desenvolvimento: as implicações de política. São Paulo em Perspectiva, São Paulo, v.19, p.34-45, 2005.

CHRISTENSEN, C. M.. The Innovator's Dilemma. Harvard Business School Press, 1997.

COOPER, D. R.; SCHINDLER, P. S.. Métodos de pesquisa em administração. 7 ed. Porto Alegre: Bookman, 2003.

COPELAND, T. E.; KOLLER, T.; MURRIN, J.. Valuation: Measuring and Managing the Value of Companies. 2 ed. New York: John Wiley \& Sons, 1995.

CYSNE, F. P.. Transferência de tecnologia entre a universidade e a indústria. Encontros Bibli, v.10, p.54/20-74, 2005.

DAMODARAN, A.. Avaliação de investimentos: ferramentas e técnicas para a determinação do valor de qualquer ativo. 5 ed. Rio de Janeiro: Qualitymark, 2003.
EDQUIST, C.. System of innovation: perspectives and challenges. In: FAGEBERG, J.; MOWERY, D.; NELSON, R. R.. The Oxford Handbook of Innovation. Oxford: Oxford University Press, 2005. p.181-208.

FARIA, A. C.; IUDÍCIBUS, S.; MARION, J. C.. Introdução à teoria da contabilidade. 5 ed. São Paulo: Atlas, 2010.

FREEMAN, C.. Chemical Process Plant: Innovation and the World Market. National Institute Economic Review 1968.

FREEMAN, C.; SOETE, L.. A Economia da Inovação Industrial. Campinas: UNICAMP, 2008.

FLIGNOR, P.; OROZCO, D.. Intangible asset and intellectual property valuation: a multidisciplinary perspective. 2006.

GITMAN, L. J.. Princípios da Administração Financeira. São Paulo: Pearson, 2010.

GOLDSCHEIDER, R.; JAROSZ, J.; MULHERN, C.. Use of the twenty-five percent rule in valuing intelectual property. 2007

PARR, R.. Royalty rates for licensing intelectual property. Hoboken: John Wilwy \& Sons, 2007.

GORDILLO, M. M.. Ciencia, Tecnología y Sociedad. Proyecto Argo. Materiales para la educación CTS. Grupo Norte, 2001.

LITAN, R.; WALLISON, P.. Beyond the GAAP. Regulation, 2003.

LUNDVALL, B. A.. National innovation systems: analytical concept and development. Tool. Industry and Innovation, v.14, n.1, p.95-119, 2007.

MARION, J. C.. Reflexões sobre ativo intangível. São Paulo: UNIVEM, 2007.

MARTINS, G. A.; THEÓPHILO, C. R.. Metodologia da investigação científica para ciências sociais aplicadas. 2 ed. São Paulo: Atlas, 2009.

METCALFE, S.. The economic foundations of technology policy: equilibrium and evolutionary perspectives. In: STONEMAN, P.. Handbook of the Economics of Innovations and Technological Change. Blackwell: Oxford, 1995. 
NATAL, Y. D.; VIVÉS, A.. Gerenciamento do processo de transferência de tecnologia. In: SIMPÓSIO DE GESTÃO DA INOVAÇÃO TECNOLÓGICA, 20. Anais. São Paulo, 1998.

OCDE. Organização para a Cooperação e Desenvolvimento Econômico. Manual de Oslo: diretrizes para a coleta e interpretação de dados sobre inovação tecnológica. 3 ed. FINEP, 2006.

RADOS, G. J. V.; DIAS, P. M.. Introdução a gestão da inovação. Florianópolis: UFSC, 2015.

ROGERS, E. M.; TAKEGAMI, S.; YIN, J.. Lessons learned about technology transfer. Technovation, v.21, n.4, p.253-261, 2001.

SANTOS, D. T. E.; SANTIAGO, L. P.. Métodos de Valoração de Tecnologias. Instituto Inovação, 2008.

SCHUMPETER, J. A.. Teoria do desenvolvimento econômico: uma investigação sobre lucros, capital, crédito, juro e o ciclo econômico. Coleção Os Economistas. São Paulo: Nova Cultural, 1997.

SHARIF, N.. Emergence and development of the National
Innovation Systems concept. Research Policy, v.35, p.745766, 2006.

SOUZA, R. O.. Valoração de Ativos Intangíveis: seu papel na transferência de tecnologias e na promoção de inovação tecnológica. Dissertação (Mestrado em Química) -

Universidade Federal do Rio de Janeiro, Rio de Janeiro, 2009.

TEBECHRANI, F. Z.. Avaliação de Concessões Rodoviárias pela Abordagem de Opções Reais. Dissertação (Mestrado em Administração) - Instituto de Ensino e Pesquisa, São Paulo, 2010.

VERASZTO, E. V.. Projeto Teckids: Educação Tecnológica no Ensino Fundamental. Dissertação (Mestrado) - Universidade Estadual de Campinas, Campinas, 2004.

VERGARA, S. C.. Projetos e relatórios de pesquisa em administração. 14 ed. São Paulo: Atlas, 2013.

WIRTZ, H.. Valuation of intellectual property: a review of approaches and methods. International Journal of Business and Management, v.7, n.9, p.40, 2012.

A CBPC - Companhia Brasileira de Produção Científica (CNPJ: 11.221.422/0001-03) detém os direitos materiais desta publicação. Os direitos referem-se à publicação do trabalho em qualquer parte do mundo, incluindo os direitos às renovações, expansões e disseminações da contribuição, bem como outros direitos subsidiários. Todos os trabalhos publicados eletronicamente poderão posteriormente ser publicados em coletâneas impressas sob coordenação da Sustenere Publishing, da Companhia Brasileira de Produção Científica e seus parceiros autorizados. Os (as) autores (as) preservam os direitos autorais, mas não têm permissão para a publicação da contribuição em outro meio, impresso ou digital, em português ou em tradução. 